Background/introduction Understanding patterns of chlamydia prevalence is important for addressing inequalities and assessing interventions. Population-based surveys are expensive; the best UK data come from the Natsal national surveys which are only available once per decade and not powered to compare prevalence in different localities. Estimates at finer spatial and temporal scales are required.

Aim(s)/objectives We aimed to estimate chlamydia prevalence from numbers of tests and diagnoses reported in surveillance data.

Methods Our method is based on a simple model for the infection, testing and treatment processes and informed by the literature on infection natural history and treatment seeking behaviour. By combining this information with surveillance data we obtain estimates of chlamydia screening rates, incidence and prevalence. We validate and illustrate the method by application to national and local-level data from England.

Results Estimates of national prevalence by sex and age group agree with results from the Natsal-3 survey. They could be improved by additional information on the number of diagnoses that were symptomatic. There is substantial local-level variation in prevalence, with more infection in deprived areas. Incidence in each sex is strongly correlated with prevalence in the other. Importantly, we find that positivity (the proportion of tests which were positive) does not provide a reliable proxy for prevalence.

Discussion/conclusion This approach provides a powerful tool to identify prevalence trends with time and location, and understand the effects of control strategies. Estimates could be more accurate if surveillance systems recorded which patients were symptomatic and the duration of symptoms before care-seeking.

\section{P032 DEVELOPING A SECTOR LED IMPROVEMENT APPROACH TO SEXUAL HEALTH}

Dianne Draper. Public Health England, London, UK

10.1136/sextrans-2016-052718.86

Background Sector-led improvement (SLI) is an approach where local authorities (LA) help each other to continuously improve. It is replacing more traditional performance frameworks, however, the approach lacks a clear methodology. We developed and piloted an evidence-based SLI approach to drive improvements in sexual health $(\mathrm{SH})$ within LAs.

Aim(s) To develop and pilot an evidenced-based SLI toolkit

Methods Key components for effective SLI were identified following a review of the published literature. These were embedded within a co-produced, peer-review toolkit which was piloted by $\mathrm{SH}$ commissioners and key stakeholders from four local authorities. The pilot focussed on delivery of local chlamydia screening programmes.

Results Several key clinical and structural issues were identified through the SLI approach including low coverage, the potential to improve partner notification outcomes, low re-testing rates, threats from a reduction in spend and unclear governance. These have been put into a local action plan to focus and drive quality improvement activities. The impact of the action plans will be the focus of a follow up meeting planned for six months after the final peer review meeting involving wider stakeholders.

Discussion The SLI toolkit offers a systematic approach to evaluating complex programme activities. It was well received locally and helped key stakeholders to gain insight, catalyse self- reflection and prioritise areas for change in order to drive quality and improvement.

\section{P033 SAFETY FIRST: COMBINED ORAL CONTRACEPTIVE PRESCRIBING IN PRIMARY CARE}

Sophie Russell. University Hospitals Bristol NHS Foundation Trust, Bristol, UK

10.1136/sextrans-2016-052718.87

Background/introduction $80 \%$ of contraceptive care occurs in the general practice (GP) setting. UK Medical Eligibility Criteria (UKMEC) provides clear guidelines for the safe provision of appropriate contraception. The Faculty of Sexual and Reproductive Health (FSRH) and the National Institute of Clinical Excellence (NICE) offer further recommendations for combined oral contraceptive pill (COCP) initiation and continuation.

Aim(s)/objectives To establish if primary care COCP prescribing was compliant with national safety and best practice guidelines.

Methods The EMIS database of an average size, inner city GP surgery was used to analyse COCP consultations between 11/10/ 2015 and 11/01/2016.

Results 56 women aged 14-39 years were prescribed the COCP. In $41 \%$ of consultations there was substandard documentation of medical eligibility.

\begin{tabular}{|c|c|}
\hline UKMEC Condition & $\%$ Consultations Lacking Documentation \\
\hline Venous thromboembolism & $28 \%$ \\
\hline Smoking status & $25 \%$ \\
\hline Blood pressure & $16 \%$ \\
\hline Body mass index & $16 \%$ \\
\hline \multicolumn{2}{|c|}{$\begin{array}{l}\text { The COCP was prescribed without specialist input for three patients with a UKMEC } 3 \text { con- } \\
\text { dition: systolic blood pressure } 143 \text {, undiagnosed breast lump and first degree family history } \\
\text { of venous thromboembolism. } 87 \% \text { patients did not receive advice about missed pill rules; } \\
\text { and } 21 \% \text { of eligible women were not advised on the benefits of long acting reversible con- } \\
\text { traception (LARC). Only } 8 \% \text { of patients were risk assessed for sexually transmitted infec- } \\
\text { tions (STIs) and no women were offered HIV screening. }\end{array}$} \\
\hline
\end{tabular}

Discussion/conclusion The safety of COCP prescribing could be enhanced by improved application of UKMEC criteria. Promotion of safe sex was not undertaken despite high incidence of STIs and local availability of LARC options.

\section{P034 ACCESS TO SEXUAL AND REPRODUCTIVE HEALTH IN THE CALAIS "JUNGLE CAMP" FOR WOMEN. A VOLUNTEER PERSPECTIVE}

\footnotetext{
${ }^{1,2}{ }^{2}$ Fionnuala Finnerty*, ${ }^{1}$ Aliza Amlani, ${ }^{2}$ Elaine Ortiz, ${ }^{1,3}$ Daniel Richardson. ${ }^{1}$ Brighton \& Sussex County Hospital, Brighton, UK; ${ }^{2}$ Hummingbird Project, Brighton, UK; ${ }^{3}$ Brighton \& Sussex Medical School, Brighton, UK
}

\subsection{6/sextrans-2016-052718.88}

Background/introduction The number of women in the "jungle" camp in Calais, France increased in 2015 but definitive numbers are unknown. Health services report these women are a difficult to access population. Multiple small groups of grassroots volunteers support initiatives in the camp and have access to vulnerable groups.

Aims/objectives To survey volunteers opinions on access to sexual and reproductive health (SRH) care in the "jungle" camp 